Contract No. and Disclaimer:

This manuscript has been authored by Savannah River Nuclear Solutions, LLC under Contract No. DE-AC09-08SR22470 with the U.S. Department of Energy. The United States Government retains and the publisher, by accepting this article for publication, acknowledges that the United States Government retains a non-exclusive, paid-up, irrevocable, worldwide license to publish or reproduce the published form of this work, or allow others to do so, for United States Government purposes. 


\title{
Plutonium Solubility in Simulated Savannah River Site Waste Solutions
}

\author{
Tracy S. Rudisill, David T. Hobbs, and Thomas B. Edwards \\ Savannah River National Laboratory \\ Aiken, SC 29808
}

\begin{abstract}
To address the accelerated disposition of the supernate and salt portions of Savannah River Site (SRS) high level waste (HLW), solubility experiments were performed to develop a predictive capability for plutonium $(\mathrm{Pu})$ solubility. A statistically designed experiment was used to measure the solubility of $\mathrm{Pu}$ in simulated solutions with salt concentrations and temperatures which bounded those observed in SRS HLW solutions. Constituents of the simulated waste solutions included: hydroxide $\left(\mathrm{OH}^{-}\right)$, aluminate $\left(\mathrm{Al}(\mathrm{OH})_{4}{ }^{-}\right)$, sulfate $\left(\mathrm{SO}_{4}{ }^{2-}\right)$, carbonate $\left(\mathrm{CO}_{3}{ }^{2-}\right)$, nitrate $\left(\mathrm{NO}_{3}{ }^{-}\right)$, and nitrite $\left(\mathrm{NO}_{2}^{-}\right)$anions. Each anion was added to the waste solution in the sodium form. The solubilities were measured at 25 and $80{ }^{\circ} \mathrm{C}$. Five sets of samples were analyzed over a 6 month period and a partial sample set was analyzed after nominally 15 months of equilibration.

No discernable time dependence of the measured $\mathrm{Pu}$ concentrations was observed except for two salt solutions equilibrated at $80{ }^{\circ} \mathrm{C}$ which contained $\mathrm{OH}^{-}$concentrations $>5 \mathrm{~mol} / \mathrm{L}$. In these solutions, the $\mathrm{Pu}$ solubility increased with time. This observation was attributed to the air oxidation of a portion of the $\mathrm{Pu}$ from $\mathrm{Pu}(\mathrm{IV})$ to the more soluble $\mathrm{Pu}(\mathrm{V})$ or $\mathrm{Pu}(\mathrm{VI})$ valence states. A data driven approach was subsequently used to develop a modified response surface model for $\mathrm{Pu}$ solubility. Solubility data from this study and historical data from the literature were used to fit the model. The model predicted the Pu solubility of the solutions from this study within the $95 \%$ confidence interval for individual predictions and the analysis of variance indicated no statistically significant lack of fit.

The Savannah River National Laboratory (SRNL) model was compared with predicted values from the Aqueous Electrolyte (AQ) model developed by OLI Systems, Inc. and a solubility prediction equation developed by Delegard and Gallagher for Hanford tank waste. The agreement between measured or values predicted by the SRNL model and values predicted by the OLI AG model was very poor. The much higher predicted concentrations by the OLI AQ model appears to be the result of the model predicting the predominate $\mathrm{Pu}$ oxidation state is $\mathrm{Pu}(\mathrm{V})$ which is reported as unstable below sodium hydroxide $(\mathrm{NaOH})$ concentrations of $6 \mathrm{M}$. There was very good agreement between the predicted $\mathrm{Pu}$ concentrations using the SRNL model and the model developed by Delegard and Gallagher with the exception of solutions that had very high $\mathrm{OH}^{-}(15 \mathrm{M})$ concentrations. The lower Pu solubilities in these solutions were attributed to the presence of $\mathrm{NO}_{3}{ }^{-}$and $\mathrm{NO}_{2}{ }^{-}$which limit the oxidation of $\mathrm{Pu}(\mathrm{IV})$ to $\mathrm{Pu}(\mathrm{V})$.
\end{abstract}




\section{Introduction}

The SRS is currently working to accelerate the disposition of the supernate and salt portions of the HLW contained in the SRS tank farm system. In particular, projects are underway to disposition salt waste according to its radionuclide content. For each disposition pathway, the $\mathrm{Pu}$ content of the waste is a dominating factor in determining the acceptance of the waste at the SRS Saltstone Facility. Since the specific activity of ${ }^{241} \mathrm{Am}$ (Am) is a factor of 55 greater than ${ }^{239} \mathrm{Pu}$, process conditions which increase its solubility in salt solutions are also a concern. The solubilities of $\mathrm{Pu}$ and $\mathrm{Am}$ in acidic waste streams resulting from $\mathrm{Pu}$ purification activities are relatively well known. When waste solutions containing these elements are neutralized, coprecipitated with other metals, and discharged into the HLW system, the solubilities change with time and with conditions under which the waste is stored or evaporated.

The solubility of $\mathrm{Pu}$ in alkaline waste solutions representative of SRS HLW has only been measured over a relative narrow range of solution compositions and temperatures. For example, Hobbs et al. [1] investigated the solubility of $\mathrm{Pu}$ and $\mathrm{U}$ in alkaline salt solutions comparable to the waste solutions to be processed by the In-Tank Precipitation Process. This study limited the temperature to between 25 and $60{ }^{\circ} \mathrm{C}$ and chemical compositions well below their bounding concentrations. These results and other Pu solubility data were evaluated and a predictive model developed as a function of the free hydroxide concentration.[2] The practical usefulness of the model is limited since other constituents in the waste solution can change the Pu solubility by as much as three orders of magnitude for a given hydroxide concentration. Americium solubility in SRS waste solutions has never been systematically studied; however, there is limited data available for Hanford tank waste [3] and in pure sodium hydroxide solutions.[4]

The objective of this work was to measure the solubility of $\mathrm{Pu}$ and $\mathrm{Am}$ in simulated SRS waste solutions over a broader range of solution compositions and temperature. A statistically designed experiment was performed in which the composition and temperature of the waste solutions were varied over expected waste tank ranges. Constituents of the simulated waste solutions included: $\mathrm{OH}^{-}, \mathrm{Al}(\mathrm{OH})_{4}^{-}, \mathrm{SO}_{4}{ }^{2-}, \mathrm{CO}_{3}{ }^{2-}, \mathrm{NO}_{3}{ }^{-}$, and $\mathrm{NO}_{2}{ }^{-}$. All of these anions could serve as complexants to form soluble Pu species. For example, Delegard reported that the solubility of $\mathrm{Pu}$ in alkaline solutions was strongly influenced by the concentrations of hydroxide, aluminate and nitrate.[5] Given the wide range of the anion concentrations, binary and ternary complexes could be important in some cases. Nitrate and nitrite can serve as oxidizing and reducing agents that would alter the redox characteristics of the solution and, therefore, influence the oxidation state of the $\mathrm{Pu}$.

Each anion was added to the waste solution in the sodium form. Solubility experiments were performed at 25 and $80^{\circ} \mathrm{C}$ to bound temperatures normally seen in SRS waste tanks.[6] Once the simulated waste solutions were prepared, weapons grade $\mathrm{Pu}$ and Am were added as a nitrate solution. Five sets of samples were analyzed over a 6 month period. A partial sample set was also analyzed after nominally 15 months of equilibration.

In the data sets from the initial 6 months of sample equilibration, significant scatter was observed for both $\mathrm{Pu}$ and Am solubilities and the Am solubilities for a significant number of test bottles were well above the Am solubilities reported in the literature.[3,4] For this reason, a filtration 
study was performed to determine if submicron, actinide-containing particles in the filtered solutions contributed to the data scatter and the elevated Am solubilities. Results from this study showed that Am particles were not completely removed during sample preparation and, thus, the Am data were not suitable for determining the Am solubility. There was some indication that submicron Pu-containing particles were not completely removed during filtration, but from a practical sense, the variability in the measured concentrations was of the same order of magnitude as the difference in the two measured values for a majority of the solutions. Thus, the $\mathrm{Pu}$ data were analyzed to develop a solubility prediction model given the composition and temperature of waste tank solutions.

\section{Experimental}

\section{Constraints on Concentration}

The range of salt concentrations and temperature expected in the SRS waste tanks are summarized in Table 1.[6] The salt concentrations and temperatures are based on historical records compiled for the SRS waste tanks in support of the corrosion control program. Each anion was assumed to be in the sodium $\left(\mathrm{Na}^{+}\right)$form.

Table 1 Range of salt concentrations and temperature in SRS waste tanks

\begin{tabular}{ccc}
\hline \hline Parameter & $\begin{array}{c}\text { Low } \\
(\mathrm{mol} / \mathrm{L})\end{array}$ & $\begin{array}{c}\text { High } \\
(\mathrm{mol} / \mathrm{L})\end{array}$ \\
\hline $\mathrm{OH}^{-}$ & 0.0001 & 15 \\
$\mathrm{Al}(\mathrm{OH})_{4}^{-}$ & 0.001 & 1 \\
$\mathrm{SO}_{4}^{2-}$ & 0.001 & 0.5 \\
$\mathrm{CO}_{3}{ }^{2-}$ & 0.001 & 1 \\
$\mathrm{NO}_{3}{ }^{-}$ & 0.1 & 6 \\
$\mathrm{NO}_{2}{ }^{-}$ & 0.1 & 6 \\
Temperature $\left({ }^{\circ} \mathrm{C}\right)$ & 25 & 80 \\
\hline
\end{tabular}

The preparation of salt solutions containing combinations of $\mathrm{OH}^{-}$and salt concentrations near the maximum levels are not possible due to the precipitation of one or more of the salts. To eliminate solution compositions that cannot be prepared, a series of constraints on the $\mathrm{OH}^{-}$and salt concentrations was utilized in the experimental design. The constraints are given by equations 1-3 where the anion and cation concentrations are in $\mathrm{mol} / \mathrm{L}$.

$$
\begin{gathered}
{\left[\mathrm{Al}(\mathrm{OH})_{4}^{-}\right] \leq \frac{1}{3}\left[\mathrm{NO}_{3}^{-}\right]} \\
{\left[\mathrm{OH}^{-}\right] \geq 0.4 \frac{\mathrm{mol}}{\mathrm{L}}+\left[\mathrm{Al}(\mathrm{OH})_{4}^{-}\right]}
\end{gathered}
$$




$$
\left[\mathrm{Na}^{+}\right]_{\text {Total }} \leq 9 \frac{\mathrm{mol}}{\mathrm{L}}
$$

The constraint on $\mathrm{Al}(\mathrm{OH})_{4}{ }^{-}$given by equation 1 is based on the stoichiometry of aluminum nitrate $\left(\mathrm{Al}\left(\mathrm{NO}_{3}\right)_{3}\right)$, the $\mathrm{Al}$ reagent used to prepare the salt solutions for the solubility measurements. The second constraint on $\mathrm{Al}(\mathrm{OH})_{4}{ }^{-}$given by equation 2 was based on $\mathrm{Al}$ solubility studies in strongly alkaline solutions [7] and ensures that $\mathrm{Al}(\mathrm{OH})_{4}{ }^{-}$remains soluble at the high end of its concentration range. The constraint on total $\mathrm{Na}^{+}$was empirically determined during this study when attempts to prepare solutions containing high salt concentrations failed even when the solution compositions were based on an experimental design utilizing constraints 1 and 2. These constraints were important inputs to the experimental design process, which is discussed in the next section.

\section{$\underline{\text { Statistical Design }}$}

The goal of this study was to generate $\mathrm{Pu}$ and Am solubility models over the space defined by the seven factors (and their intervals of possible values) shown in Table 1. Historical data of interest to this study were available for Pu solubility [1,2, and 7-9] but not for Am solubility. A total of $71 \mathrm{Pu}$ solubility data points which met the restriction on the factor space imposed by the three constraints were used as the starting point for the development of the test matrix for this study. This was true even for data that extended slightly beyond the region defined by Table 1 (i.e., not all of the species were used to prepare the salt solutions). Thus, the test matrix designed for this study was selected to complement the previous Pu solubility measurements while providing a good initial basis for the study of the relationship between Am solubility and the factors of Table 1.

The Pu model of interest in this study is a response surface model in the 7 factors of Table 1 except for the quadratic temperature term, which is not of interest. Thus, the model of interest is made up of an intercept term, 7 main effect terms, 6 quadratic (or squared) terms, and 21 twoway interaction terms for a total of 35 terms. For the initial investigation of Am solubility, the model form of interest was a first-order model in the 7 factors.

Statistical routines are available to assist with experimental design problems. One such routine is the D-Optimal routine available in JMP Version 3.2.6.[10] This routine selects a design of a specified size (i.e., number of design points) from a set of candidate points that optimizes the fitting of a specified model form. The optimization is relative to efficiency measures of the fitted model. (The optimal design criterion used by JMP Version 3.2.6 is D-optimality (i.e., to maximize the D-efficiency), where D-efficiency is a measure of design efficiency that is related to the determinant of the variance-covariance matrix of the design. [11])

To use this routine, there was a need to generate a set of candidate design points that were within the factor space of Table 1 and that satisfied constraints 1-3. This was accomplished by generating an initial, space-filling design using a modified, orthogonal Latin hypercube (OLH) approach. An OLH design is a space filling design that provides an opportunity for independently estimating main effects.[12] However, due to the restrictions imposed by constraints 1-3, the OLH was modified to satisfy these constraints. Temperature was excluded 
from this process, and each of the OLH points generated for the other factors was used to define candidate points, one at $25^{\circ} \mathrm{C}$ and one at $80^{\circ} \mathrm{C}$.

A set of special candidate design points was added to the OLH points. These points were added (at temperatures of 25 and $80{ }^{\circ} \mathrm{C}$ ) to represent possible solution concentrations that may result from SRS evaporator operations (i.e., high $\mathrm{OH}^{-}$and low salt concentrations). The $\mathrm{OLH}$ and special candidate design points were submitted to the D-Optimal routines from which 8 optimal points were selected to support the fitting of a first-order model relating Am solubility to the 7 factors of this study. The D-Optimal routine of JMP 3.2.6 was used a second time to define optimal points for fitting the modified response surface model for Pu solubility. For this run, the set of candidate design points were formed by adding the historical data which met the restriction on the factor space imposed by the three constraints, the OLH points, the special candidate design points, and the 8 points selected to support fitting a first-order model for Am solubility. The routine was asked to complement the historical 71 data points and the 8 points selected for the Am model with 12 additional, "optimal" points for a total of 91 design points. The design points for the final test matrix and the available data are illustrated in Figure 1.

\section{Preparation of Salt Solutions}

The 20 salt solutions specified as design points for the Pu and Am solubility experiments were prepared using ACS certified reagents. The starting materials are shown in Table 2.

Table 2 Starting materials used for preparation of salt solutions

\begin{tabular}{lcc}
\hline \hline \multicolumn{1}{c}{ Chemical } & $\begin{array}{c}\text { Concentration } \\
(\mathrm{mol} / \mathrm{L})\end{array}$ & Formula \\
\hline sodium hydroxide $(\mathrm{NaOH})$ & 19.11 & $\mathrm{NaOH}$ \\
aluminum nitrate nonahydrate $\left(\mathrm{Al}\left(\mathrm{NO}_{3}\right)_{3}\right)$ & & $\mathrm{Al}\left(\mathrm{NO}_{3}\right)_{3} \bullet 9 \mathrm{H}_{2} \mathrm{O}$ \\
sodium sulfate decahydrate $\left(\mathrm{Na}_{2} \mathrm{SO}_{4}\right)$ & & $\mathrm{Na}_{2} \mathrm{SO}_{4} \bullet 10 \mathrm{H}_{2} \mathrm{O}$ \\
sodium carbonate monohydrate $\left(\mathrm{Na}_{2} \mathrm{CO}_{3}\right)$ & & $\mathrm{Na}_{2} \mathrm{CO}_{3} \cdot \mathrm{H}_{2} \mathrm{O}$ \\
sodium nitrate $\left(\mathrm{NaNO}_{3}\right)$ & $\mathrm{NaNO}_{3}$ \\
sodium nitrite $\left(\mathrm{NaNO}_{2}\right)$ & $\mathrm{NaNO}_{2}$ \\
\hline
\end{tabular}

The solutions were prepared by initially transferring the desired amounts of $19.11 \mathrm{~mol} / \mathrm{L} \mathrm{NaOH}$ to a beaker. The target amount of $\mathrm{Al}\left(\mathrm{NO}_{3}\right)_{3}$ was then dissolved in 4-5 mL of deionized water in a separate beaker and mixed with the $\mathrm{NaOH}$ until all solids dissolved. The beaker containing the $\mathrm{Al}\left(\mathrm{NO}_{3}\right)_{3}$ was rinsed with 2, 1-2 mL aliquots of deionized water. The target masses of $\mathrm{Na}_{2} \mathrm{SO}_{4}$, $\mathrm{Na}_{2} \mathrm{CO}_{3}, \mathrm{NaNO}_{3}$, and $\mathrm{NaNO}_{2}$ were then added to the caustic solution in the order indicated. Each salt was dissolved before the next was added to the solution. The contents of the beaker were stirred and heated (at $<80^{\circ} \mathrm{C}$ ) when necessary to dissolve the salts. A watch glass containing water was placed on top of the beaker to reduce evaporation losses; however, periodically it was necessary to add deionized water to the beaker to replace evaporated water or promote the dissolution of one of the salts. After dissolving the salts, the solutions were transferred to a graduated cylinder. The beaker was rinsed with 3, 1-2 mL aliquots of deionized water. The contents of the graduated cylinder were then diluted to a volume of $100 \mathrm{~mL}$. The salt solutions were transferred to plastic bottles and then back into the graduated cylinder to mix the 
solution and ensure the residual volume remaining in the cylinder was the same composition as the solution transferred to the bottle. This procedure was repeated 3 times.

During the preparation of the salt solutions, it was necessary to reduce the $\mathrm{SO}_{4}{ }^{2-}$ or $\mathrm{CO}_{3}{ }^{2-}$ concentrations of several solutions to completely dissolve the $\mathrm{Na}_{2} \mathrm{SO}_{4}$ and $\mathrm{Na}_{2} \mathrm{CO}_{3}$. In addition, the final volume of several solutions was slightly greater than $100 \mathrm{~mL}$. During solution preparation, deionized water was added to aid in the dissolution of the salts. After the dissolution of the starting materials, the final volume of the solutions could not be evaporated below $100 \mathrm{~mL}$ without the precipitation of solids. The actual concentrations of the salt solutions and equilibration temperature are given in Table 3.

Table 3 Actual concentration of salt solutions

\begin{tabular}{cccccccc}
\hline \hline Solution & $\begin{array}{c}\mathrm{OH}^{-} \\
(\mathrm{mol} / \mathrm{L})\end{array}$ & $\begin{array}{c}\mathrm{Al}(\mathrm{OH})_{4}{ }^{-} \\
(\mathrm{mol} / \mathrm{L})\end{array}$ & $\begin{array}{c}\mathrm{SO}_{4}{ }^{2-} \\
(\mathrm{mol} / \mathrm{L})\end{array}$ & $\begin{array}{c}\mathrm{CO}_{3}{ }^{2-} \\
(\mathrm{mol} / \mathrm{L})\end{array}$ & $\begin{array}{c}\mathrm{NO}_{3}{ }^{-} \\
(\mathrm{mol} / \mathrm{L})\end{array}$ & $\begin{array}{c}\mathrm{NO}_{2}{ }^{-} \\
(\mathrm{mol} / \mathrm{L})\end{array}$ & $\begin{array}{c}\mathrm{Temp} \\
\left({ }^{\circ} \mathrm{C}\right)\end{array}$ \\
\hline $1 \mathrm{~A}$ & 15.0 & 0.001 & 0 & 0.001 & 0.100 & 0.100 & 25 \\
$2 \mathrm{~A}$ & 15.0 & 0.001 & 0 & 0.001 & 0.100 & 0.100 & 80 \\
$3 \mathrm{~A}$ & 5.51 & 0.017 & 0.016 & 0.600 & 0.752 & 0.815 & 80 \\
4 & 0.873 & 0.132 & 0.011 & 0.888 & 4.88 & 1.27 & 25 \\
5 & 0.872 & 0.132 & 0.010 & 0.888 & 4.88 & 1.27 & 80 \\
6 & 2.27 & 0.663 & 0.207 & 0.059 & 2.47 & 2.99 & 80 \\
7 & 1.78 & 0.113 & 0.121 & 0.363 & 0.626 & 5.43 & 80 \\
8 & 1.48 & 0.372 & 0.312 & 0.215 & 1.43 & 3.70 & 25 \\
$9 \mathrm{~A}$ & 3.35 & 0.603 & 0.214 & 0.248 & 2.54 & 0.867 & 25 \\
$10 \mathrm{~A}$ & 2.90 & 0.756 & 0.250 & 0.222 & 2.99 & 0.628 & 80 \\
$11 \mathrm{~A}$ & 5.64 & 0.109 & 0.242 & 0.282 & 0.343 & 0.936 & 80 \\
12 & 2.61 & 0.046 & 0.083 & 0.885 & 0.160 & 3.41 & 25 \\
13 & 1.22 & 0.601 & 0.111 & 0.036 & 4.15 & 1.82 & 25 \\
14 & 0.454 & 0.031 & 0.108 & 0.073 & 3.64 & 3.42 & 25 \\
15 & 1.29 & 0.741 & 0.181 & 0.950 & 2.50 & 0.169 & 25 \\
16 & 1.29 & 0.741 & 0.181 & 0.950 & 2.50 & 0.169 & 80 \\
17 & 2.07 & 0.050 & 0.467 & 0.826 & 0.250 & 0.794 & 25 \\
18 & 0.861 & 0.067 & 0.181 & 0.950 & 0.466 & 0.111 & 80 \\
19 & 0.628 & 0.007 & 0.436 & 0.446 & 0.515 & 0.418 & 80 \\
20 & 2.63 & 0.025 & 0.084 & 0.013 & 0.160 & 0.146 & 80 \\
\hline
\end{tabular}

Once the salt solutions were prepared, nominally $10 \mathrm{~mL}$ of each solution were transferred to 6 , $15 \mathrm{~mL}$ plastic bottles. The intent of preparing 6 sample bottles for each solution was to allow the removal of a separate bottle each time the solutions were sampled. This procedure eliminated the need to remove the entire solution from a temperature-controlled environment during sampling and allowed the solutions to be maintained at the desired temperature using equipment which was not radioactively contaminated.

The weapons grade $\mathrm{Pu}$ added to the salt solutions was initially purified and concentrated by anion exchange. Likewise, Am recovered from the raffinate of a $\mathrm{Pu}$ anion exchange column run was purified and concentrated using a chelating resin. The $\mathrm{Pu}^{4+}$ and $\mathrm{Am}^{3+}$ nitrate solutions were 
used to prepare a stock solution containing $4.18 \times 10^{-3} \mathrm{~mol} / \mathrm{L} \mathrm{Pu}$ and $4.15 \times 10^{-3} \mathrm{~mol} / \mathrm{L} \mathrm{Am}$ $(1000 \mu \mathrm{g} / \mathrm{mL}$ each $)$ in nominally $1 \mathrm{~mol} / \mathrm{L}$ nitric acid $\left(\mathrm{HNO}_{3}\right)$. Each of the salt solution sample bottles was spiked with $50 \mu \mathrm{L}$ of the $\mathrm{Pu} / \mathrm{Am}$ stock solution. During the $\mathrm{Pu} / \mathrm{Am}$ additions, the sample bottles were handled in a way to prevent the outside from becoming contaminated and were placed in $250 \mathrm{~mL}$ plastic bottles which provided secondary containment for the solutions. One to 3 sample bottles were placed in each of the bottles. The $250 \mathrm{~mL}$ bottles were secured in New Brunswick Scientific Innova 4080 Incubator Shakers to maintain the solutions at the desired temperature. The temperature of the incubator shakers were continuously monitored using calibrated thermistors. Variations in temperature were held to less than $\pm 1^{\circ} \mathrm{C}$.

\section{$\underline{\text { Sampling and Analysis of Salt Solutions }}$}

Five sets of the salt solution samples were analyzed over a 6 month period. A partial sample set was also analyzed after nominally 15 months of equilibration. To prepare the samples for analysis, 5-8 $\mathrm{mL}$ of solution were removed from a sample bottle using a $10 \mathrm{~mL}$ disposable syringe with a piece of plastic tubing attached to facilitate reaching into the sample bottle. The solution was expelled through an Acrodisc ${ }^{\circledR} 0.45 \mu \mathrm{m}$ Versapor ${ }^{\circledR}$ membrane disk filter into a clean glass vial. A $1 \mathrm{~mL}$ aliquot of the filtered solution was slowly transferred (to reduce the rate of gas evolution) by pipette into a glass sample vial containing 2 or $4 \mathrm{~mL}$ of $5 \mathrm{~mol} / \mathrm{L}^{\mathrm{HNO}_{3}}$. The $4 \mathrm{~mL}$ aliquot of acid was used to neutralize salt solution samples containing $15 \mathrm{~mol} / \mathrm{L} \mathrm{NaOH}$; a 2 $\mathrm{ml}$ aliquot of acid was used to neutralize the remainder of the samples. The resulting $\mathrm{HNO}_{3}$ concentrations of the samples were 1-3 mol/L. The acidified samples were analyzed for $\mathrm{Pu}$ $\left({ }^{238} \mathrm{Pu}\right.$ and $\left.{ }^{239} \mathrm{Pu} /{ }^{240} \mathrm{Pu}\right)$ by thenolytrifluoroacetone (TTA) extraction and alpha pulse height analysis (APHA). The Am concentration was measured by gamma pulse height analysis (GPHA).

Since 11 of the salt solutions were equilibrated at $80{ }^{\circ} \mathrm{C}$, care was taken during the sampling procedure to ensure that the solutions stayed at or near temperature to prevent the precipitation of $\mathrm{Pu}$ and $\mathrm{Am}$ as the solutions cooled. To maintain the salt solutions at this temperature, a drying oven was used to preheat to $80^{\circ} \mathrm{C}$ the syringes, tubing, filter disks, glass vials, and pipette tips used in the sampling procedure. When the sample bottles were removed from the incubator shaker, the bottle(s) not being sampled were placed in the drying oven to maintain the solution(s) at $80{ }^{\circ} \mathrm{C}$.

To check the consistency of the Pu and Am analyses, blank and standard Pu/Am solutions were analyzed with each set of salt solutions. The blank solutions were randomly selected samples of the 20 salt solutions which did not contain $\mathrm{Pu}$ and $\mathrm{Am}$. A standard solution containing $2.09 \times 10^{-6} \mathrm{~mol} / \mathrm{L} \mathrm{Pu}$ and $2.07 \times 10^{-6} \mathrm{~mol} / \mathrm{L} \mathrm{Am}(0.5 \mu \mathrm{g} / \mathrm{mL}$ each $)$ was prepared by diluting a $50 \mu \mathrm{L}$ aliquot of the $\mathrm{Pu} / \mathrm{Am}$ stock solution used to prepare the salt solutions.

\section{$\underline{\text { Filtration Study }}$}

Substantial scatter was observed in both the Pu and Am solubility data from samples analyzed during the first 6 months of the study and the Am solubilities were well above the limited data available from the literature.[3,4] To address these issues, a filtration study was performed using the sixth set of samples equilibrated at $25^{\circ} \mathrm{C}$ to determine if submicron, actinide-containing 
particles in the filtered solutions contributed to the data scatter and the elevated Am solubilities. The sample preparation was performed by removing a 4-5 $\mathrm{mL}$ aliquot of salt solution from a sample bottle using a disposable syringe and expelling through a $0.45 \mu \mathrm{m}$ disk filter into a clean glass vial. A second 4-5 mL aliquot of salt solution was subsequently removed from the sample bottle using a new syringe and expelled through either a 0.02 or $0.1 \mu \mathrm{m}$ filter disk into a clean glass vial. The $0.1 \mu \mathrm{m}$ sample disk was only used for the sample containing $15 \mathrm{~mol} / \mathrm{L} \mathrm{NaOH}$. The high viscosity of the solution prevented the use of the $0.02 \mu \mathrm{m}$ filter disk. Once the solution was split into two samples, acidification of the solutions and $\mathrm{Pu}$ and $\mathrm{Am}$ analyses were performed in the same manner as discussed above.

\section{Results and Discussion}

The $\mathrm{Pu}$ solubilities measured in each of the salt solutions as a function of the equilibration time are summarized in Figures 2 and 3. The solubility data for Am are not presented since the filtration study confirmed that submicron particles were not removed by the $0.45 \mu \mathrm{m}$ filter disks used to prepare the samples and their presence significantly biased the measured Am concentrations high. The results from the filtration study for both $\mathrm{Pu}$ and $\mathrm{Am}$ are shown in Figure 4. Comparison of the analyzed Pu concentrations for samples prepared using the 0.45 and $0.02 \mu \mathrm{m}$ filter disks shows some indication that submicron particles were also present in these solutions; however, from a practical standpoint, the variability in the solubility data for each salt solution was approximately equal or greater than the difference in the two measured values for a majority of the solutions.

The $\mathrm{Pu}$ concentration data show significant variability; however, no discernable time dependence was observed except for two salt solutions equilibrated at $80{ }^{\circ} \mathrm{C}$ which contained $\mathrm{OH}^{-}$ concentrations $>5 \mathrm{~mol} / \mathrm{L}$. In these solutions, the $\mathrm{Pu}$ solubility generally increased with time. An increase in solubility is consistent with the air oxidation of some of the $\mathrm{Pu}$ from the $\mathrm{Pu}(\mathrm{IV})$ valence to the more soluble $\mathrm{Pu}(\mathrm{V})$ or $\mathrm{Pu}(\mathrm{VI})$ valence states.[13] Since an increase in $\mathrm{Pu}$ solubility with time was not observed in the high $\mathrm{OH}^{-}(>5 \mathrm{~mol} / \mathrm{L})$ salt solution equilibrated at $25^{\circ} \mathrm{C}$, the effect of the higher temperature on the kinetics of the oxidation process may also be important. To illustrate the variability of the data, the standard deviations of the Pu solubilities for each salt solution are shown in Figure 5. The average value for all salt solutions was $\pm 1.96 \times 10^{-6} \mathrm{~mol} / \mathrm{L}$. The relative standard deviations (see also Figure 5) ranged from approximately 9 to $93 \%$; although, a majority of the values were less than approximately $40 \%$.

The variability associated with the measured solubilities include both experimental and analytical contributions. A major source of variability in the data is likely a time dependence which was not discernable in the solubility (except for the two salt solutions discussed above) as the $\mathrm{Pu}$ concentration approached an equilibrium value. Other sources of experimental error would include: the preparation of the salt solutions, control of the temperature, sample preparation, and changes in the $\mathrm{CO}_{3}{ }^{2-}$ concentration due to the absorption of carbon dioxide from the air during solution handling. Of these four sources of error, the uncertainty in the data due to sample preparation is the most significant. This is especially true of the samples equilibrated at $80^{\circ} \mathrm{C}$; although, a significant effort was made to maintain the solutions at temperature prior to 
neutralization. The relative uncertainty associated with the TTA extractions and APHA for Pu and the GPHA for Am were between 5 and 10\%.

\section{$\underline{\mathrm{Pu} \text { Solubility Modeling }}$}

A data-driven approach was used in developing models for Pu solubility. The solubility data from the historical studies discussed above as well as the current solubility results were included in this effort. The response was taken to be $\mathrm{Pu}$ concentration expressed in $\mathrm{mol} / \mathrm{L}$. The average of the measured concentrations for each solution bottle was used to represent the current study results. The modeling was conducted using JMP Version 7.0.2.[14] The potential explanatory variables for the modeling effort included linear terms for the experimental factors (i.e., the columns of Table 3) as well as terms for all possible two-way interactions and for quadratic effects for these factors. The approach yielded a model with a coefficient of determination $\left(\mathrm{R}^{2}\right)$ value over 0.99 , which implied that the resulting model explained over $99 \%$ of the variation in the response values. However, there was an indication of a statistically significant lack of fit for the model as well as a consensus among the authors that the effort had led to a model that over fit the data.

An additional data-driven approach was pursued to find a more parsimonious model. In this effort, the response variable was the common logarithms of the average solubilities of the available data as the response variable. This effort led to the modeling outcome provided in equation 4 . The fitted model is given by:

$$
\begin{aligned}
\log _{10}[\mathrm{Pu} \text { Solubility }(\mathrm{mol} / \mathrm{L})]= & -6.81+0.471\left[\mathrm{Al}(\mathrm{OH})_{4}^{-}\right]+1.01\left[\mathrm{CO}_{3}^{2-}\right] \\
& -0.0104\left[\mathrm{NO}_{2}^{-}\right]+0.345\left[\mathrm{OH}^{-}\right] \\
& -0.211\left(\left[\mathrm{OH}^{-}\right]-2.29\right)\left(\left[\mathrm{NO}_{2}^{-}\right]-1.04\right) \\
& -0.0350\left(\left[\mathrm{OH}^{-}\right]-2.29\right)\left(\left[\mathrm{OH}^{-}\right]-2.29\right)
\end{aligned}
$$

The $\mathrm{R}^{2}$ value for the fitted model was 0.859 , which indicates that this model explains $85.9 \%$ of variation in the response values. An analysis of variance also indicated no statistically significant lack of fit for this model.

Table 4 provides a listing of the results of the fitted model for the Pu solubilities of this study. The table includes the bottle identifier, the average Pu solubility for each bottle, the model prediction of the solubility, a 95\% confidence interval (lower and upper limits) for the mean $\mathrm{Pu}$ solubility (i.e., the expected solubility for a bottle), and a 95\% confidence interval (lower and upper limits) for an individual response (i.e., a new experimental trial). All of the current study results fall within the $95 \%$ confidence interval for individual predictions. 
Table 4 Model predictions versus current experimental results

\begin{tabular}{ccccccc}
\hline \hline Bottle & $\begin{array}{c}\text { Pu } \\
\text { Concentration }\end{array}$ & $\begin{array}{c}\text { Model } \\
\text { Prediction }\end{array}$ & $\begin{array}{c}95 \% \\
\text { Confidence } \\
\text { Lower Limit } \\
\text { Mean } \\
(\text { mol/L) }\end{array}$ & $\begin{array}{c}95 \% \\
\text { Confidence } \\
\text { Upper Limit } \\
\text { Mean } \\
(\text { mol/L) }\end{array}$ & $\begin{array}{c}95 \% \\
\text { Confidence } \\
\text { Lower Limit } \\
\text { Individual } \\
\text { (mol/L) }\end{array}$ & $\begin{array}{c}\text { Confidence } \\
\text { Upper Limit } \\
\text { Individual } \\
\text { (mol/L) }\end{array}$ \\
\hline $1 \mathrm{~A}$ & $1.40 \mathrm{E}-05$ & $1.66 \mathrm{E}-05$ & $6.48 \mathrm{E}-06$ & $4.24 \mathrm{E}-05$ & $3.25 \mathrm{E}-06$ & $8.46 \mathrm{E}-05$ \\
$2 \mathrm{~A}$ & $2.07 \mathrm{E}-05$ & $1.66 \mathrm{E}-05$ & $6.48 \mathrm{E}-06$ & $4.24 \mathrm{E}-05$ & $3.25 \mathrm{E}-06$ & $8.46 \mathrm{E}-05$ \\
$3 \mathrm{~A}$ & $2.08 \mathrm{E}-05$ & $3.01 \mathrm{E}-05$ & $1.56 \mathrm{E}-05$ & $5.81 \mathrm{E}-05$ & $6.82 \mathrm{E}-06$ & $1.33 \mathrm{E}-04$ \\
4 & $8.53 \mathrm{E}-06$ & $2.68 \mathrm{E}-06$ & $1.60 \mathrm{E}-06$ & $4.47 \mathrm{E}-06$ & $6.42 \mathrm{E}-07$ & $1.12 \mathrm{E}-05$ \\
5 & $3.68 \mathrm{E}-06$ & $2.67 \mathrm{E}-06$ & $1.60 \mathrm{E}-06$ & $4.47 \mathrm{E}-06$ & $6.42 \mathrm{E}-07$ & $1.12 \mathrm{E}-05$ \\
6 & $2.95 \mathrm{E}-06$ & $2.09 \mathrm{E}-06$ & $1.03 \mathrm{E}-06$ & $4.26 \mathrm{E}-06$ & $4.62 \mathrm{E}-07$ & $9.47 \mathrm{E}-06$ \\
7 & $1.72 \mathrm{E}-06$ & $4.27 \mathrm{E}-06$ & $1.90 \mathrm{E}-06$ & $9.61 \mathrm{E}-06$ & $8.97 \mathrm{E}-07$ & $2.03 \mathrm{E}-05$ \\
8 & $5.98 \mathrm{E}-06$ & $3.05 \mathrm{E}-06$ & $1.80 \mathrm{E}-06$ & $5.19 \mathrm{E}-06$ & $7.28 \mathrm{E}-07$ & $1.28 \mathrm{E}-05$ \\
$9 \mathrm{~A}$ & $6.40 \mathrm{E}-06$ & $7.33 \mathrm{E}-06$ & $4.48 \mathrm{E}-06$ & $1.20 \mathrm{E}-05$ & $1.77 \mathrm{E}-06$ & $3.03 \mathrm{E}-05$ \\
$10 \mathrm{~A}$ & $3.38 \mathrm{E}-06$ & $6.27 \mathrm{E}-06$ & $3.47 \mathrm{E}-06$ & $1.13 \mathrm{E}-05$ & $1.46 \mathrm{E}-06$ & $2.69 \mathrm{E}-05$ \\
$11 \mathrm{~A}$ & $1.15 \mathrm{E}-05$ & $1.37 \mathrm{E}-05$ & $7.52 \mathrm{E}-06$ & $2.49 \mathrm{E}-05$ & $3.18 \mathrm{E}-06$ & $5.89 \mathrm{E}-05$ \\
12 & $1.18 \mathrm{E}-05$ & $6.32 \mathrm{E}-06$ & $2.71 \mathrm{E}-06$ & $1.48 \mathrm{E}-05$ & $1.30 \mathrm{E}-06$ & $3.07 \mathrm{E}-05$ \\
13 & $2.37 \mathrm{E}-06$ & $1.11 \mathrm{E}-06$ & $6.70 \mathrm{E}-07$ & $1.83 \mathrm{E}-06$ & $2.67 \mathrm{E}-07$ & $4.60 \mathrm{E}-06$ \\
14 & $1.05 \mathrm{E}-06$ & $1.59 \mathrm{E}-06$ & $6.51 \mathrm{E}-07$ & $3.89 \mathrm{E}-06$ & $3.20 \mathrm{E}-07$ & $7.92 \mathrm{E}-06$ \\
15 & $6.55 \mathrm{E}-06$ & $5.19 \mathrm{E}-06$ & $2.65 \mathrm{E}-06$ & $1.02 \mathrm{E}-05$ & $1.17 \mathrm{E}-06$ & $2.31 \mathrm{E}-05$ \\
16 & $2.30 \mathrm{E}-06$ & $5.19 \mathrm{E}-06$ & $2.65 \mathrm{E}-06$ & $1.02 \mathrm{E}-05$ & $1.17 \mathrm{E}-06$ & $2.31 \mathrm{E}-05$ \\
17 & $5.57 \mathrm{E}-06$ & $5.41 \mathrm{E}-06$ & $3.30 \mathrm{E}-06$ & $8.88 \mathrm{E}-06$ & $1.31 \mathrm{E}-06$ & $2.24 \mathrm{E}-05$ \\
18 & $8.52 \mathrm{E}-07$ & $1.31 \mathrm{E}-06$ & $7.37 \mathrm{E}-07$ & $2.32 \mathrm{E}-06$ & $3.07 \mathrm{E}-07$ & $5.58 \mathrm{E}-06$ \\
19 & $7.02 \mathrm{E}-07$ & $3.43 \mathrm{E}-07$ & $2.38 \mathrm{E}-07$ & $4.96 \mathrm{E}-07$ & $8.62 \mathrm{E}-08$ & $1.37 \mathrm{E}-06$ \\
20 & $2.58 \mathrm{E}-06$ & $1.50 \mathrm{E}-06$ & $9.45 \mathrm{E}-07$ & $2.37 \mathrm{E}-06$ & $3.66 \mathrm{E}-07$ & $6.13 \mathrm{E}-06$ \\
\hline
\end{tabular}

$\underline{\text { Model Comparisons }}$

We also compared the measured values and the SRNL prediction model with predicted values from the AQ model developed by OLI Systems, Inc [15] and a solubility prediction equation developed by Delegard and Gallagher.[3] The AQ model does not include $\mathrm{NaNO}_{2}$ species. Thus, for the calculations we used the sum of the nitrate and nitrite concentrations as the nitrate concentration for the model calculations. The prediction equation developed by Delegard and Gallagher, referred to in this paper as the Hanford Model, is only a function of the hydroxide, nitrate and aluminate concentrations (equation 5),

$$
\begin{aligned}
\log _{10}[\mathrm{Pu} \text { solubility }] & =-5.6688+0.1385 \log _{10}\left[\mathrm{NaNO}_{3}\right]-0.1794 \log _{10}[\mathrm{NaOH}] \\
& +0.1175 \log _{10}\left[\mathrm{NaAl}(\mathrm{OH})_{4}\right]+0.125\left(\log _{10}\left[\mathrm{NaNO}_{3}\right]\right)^{2} \\
& +0.0090\left(\log _{10}\left[\mathrm{NaAl}(\mathrm{OH})_{4}\right]\right)^{2}
\end{aligned}
$$

where $\left[\mathrm{Pu}\right.$ solubility], $[\mathrm{NaOH}],\left[\mathrm{NaNO}_{3}\right]$, and $\left[\mathrm{NaAl}(\mathrm{OH})_{4}\right]$ are concentrations expressed in units of $\mathrm{mol} / \mathrm{L}$. 
Figure 6 provides a plot of the measured $\mathrm{Pu}$ concentrations, the predicted $\mathrm{Pu}$ concentrations from the SRNL response surface model, the 95\% lower and upper confidence limit Pu concentrations from the SRNL model and the predicted Pu concentrations from the OLI AQ and Hanford models across the test series. Inspection of the figure shows that there is poor agreement between the measured or the SRNL-predicted Pu concentrations with those predicted by the OLI AQ model. In general, the OLI AQ model predicts Pu concentrations 10-100 times greater than that measured. With exception of Tests $1 \mathrm{~A}$ and $2 \mathrm{~A}$, there is very good agreement between the predicted $\mathrm{Pu}$ concentrations using the SRNL and Hanford models. Tests 1A and 2A are solutions that have very high $\mathrm{OH}^{-}$concentrations $(15.0 \mathrm{M})$.

The much higher predicted concentrations of Pu by the OLI AQ model appear to be the result of the model predicting that the predominant oxidation state of the $\mathrm{Pu}$ in solution is $\mathrm{Pu}(\mathrm{V})$. Plutonium (III), $\mathrm{Pu}(\mathrm{IV}), \mathrm{Pu}(\mathrm{V}), \mathrm{Pu}(\mathrm{VI})$ and $\mathrm{Pu}(\mathrm{VII})$ oxidation states are well known to exist over a wide variety of conditions in aqueous solutions. However, only $\mathrm{Pu}(\mathrm{IV}), \mathrm{Pu}(\mathrm{V})$ and $\mathrm{Pu}(\mathrm{VI})$ are reported to be stable in strongly alkaline solutions with $\mathrm{Pu}(\mathrm{IV})$ and $\mathrm{Pu}(\mathrm{V})$ reported to be more stable than $\mathrm{Pu}(\mathrm{VI})$. Plutonium (V) is reported to be unstable below a $\mathrm{NaOH}$ concentration of $6 \mathrm{M}$. [16] Thus, one would expect that the major solution phase oxidation state to be $\mathrm{Pu}(\mathrm{IV})$ except for Tests $1 \mathrm{~A}$ and $2 \mathrm{~A}$, which have $\mathrm{NaOH}$ concentrations of $15 \mathrm{M}$. Since the predominant $\mathrm{Pu}$ oxidation state in the test solutions in this study is Pu(IV), the OLI AQ model is not appropriate for predicting the solubility of alkaline salt solutions in equilibrium with $\mathrm{Pu}(\mathrm{IV})$ solids.

The measurements of $\mathrm{Pu}$ solubility in pure $\mathrm{OH}^{-}$solutions including those well above $5 \mathrm{M}^{\text {in }} \mathrm{OH}^{-}$ were reportedly carried out in aerated solutions.[16] In the SRNL tests, the solutions were prepared using an acidic $\mathrm{Pu}\left(\mathrm{NO}_{3}\right)_{4}$ solution and placed in bottles in contact with air. Oxygen $\left(\mathrm{O}_{2}\right)$ would also be expected to be produced during the course of the experiment due to alpharadiolysis of $\mathrm{NO}_{3}{ }^{-}$. Thus, the test solutions are considered to be conducted under aerobic conditions. Tests conducted at $80{ }^{\circ} \mathrm{C}$ would be expected to have a lower partial pressure of $\mathrm{O}_{2}$ than the tests at $25^{\circ} \mathrm{C}$ given that the solubility of gases in solution is reduced with increasing temperature.

In almost all of the previous solubility studies, the test solutions have been either a single chemical component (e.g., pure $\mathrm{NaOH}$ ) or a mixture of two or three components. In this study each test solutions contained all six anionic components, with the exception of Test $1 \mathrm{~A}$ and $2 \mathrm{~A}$, which did not contain any sulfate. Note, we attempted to add sulfate $(0.001 \mathrm{M})$ to these test solutions, but even a small amount of $\mathrm{Na}_{2} \mathrm{SO}_{4}$ would not dissolve.

In an earlier study over a much more limited range of $\mathrm{OH}^{-}$concentrations $(0.5-2.0 \mathrm{M})$, increasing concentrations of $\mathrm{SO}_{4}{ }^{2-}(0.018-0.41 \mathrm{M}), \mathrm{Al}(\mathrm{OH})_{4}{ }^{-}(0.051-0.36 \mathrm{M})$ and $\mathrm{CO}_{3}{ }^{2-}$ $(0.011-0.28 \mathrm{M})$ resulted in increased Pu solubility.[1] These tests also indicated that increasing concentrations of $\mathrm{NO}_{3}{ }^{-}(0.92-4.2 \mathrm{M})$ and $\mathrm{NO}_{2}{ }^{-}(0.097-2.0 \mathrm{M})$ decreased $\mathrm{Pu}$ solubility. Barney et al. [16] have also reported a similar influence of $\mathrm{NO}_{2}{ }^{-}$in mixed $\mathrm{NO}_{2}{ }^{-}$and $\mathrm{OH}^{-}$solutions. In Tests $1 \mathrm{~A}$ and $2 \mathrm{~A}$, the concentrations of the $\mathrm{Al}(\mathrm{OH})_{4}{ }^{-}$and $\mathrm{CO}_{3}{ }^{2-}$ are about two orders of magnitude lower than those of the $\mathrm{NO}_{3}{ }^{-}$and $\mathrm{NO}_{2}{ }^{-}$. Thus, we postulate that the concentrations of $\mathrm{NO}_{3}{ }^{-}$and $\mathrm{NO}_{2}{ }^{-}$are limiting the oxidation of $\mathrm{Pu}(\mathrm{IV})$ to $\mathrm{Pu}(\mathrm{V})$ and, consequently, the measured $\mathrm{Pu}$ 
concentrations are well below those reported previously in very concentrated $\mathrm{NaOH}$ solutions.[3,7]

\section{Conclusions}

A statistically designed experiment was used to measure the solubility of $\mathrm{Pu}$ in 20 solutions with varying salt concentrations $\left(\mathrm{OH}^{-}, \mathrm{Al}(\mathrm{OH})_{4}{ }^{-}, \mathrm{SO}_{4}{ }^{2-}, \mathrm{CO}_{3}{ }^{2-}, \mathrm{NO}_{3}{ }^{-}\right.$, and $\left.\mathrm{NO}_{2}{ }^{-}\right)$and temperature $\left(25\right.$ or $\left.80^{\circ} \mathrm{C}\right)$. No discernable time dependence of the measured concentrations was observed except for two salt solutions equilibrated at $80^{\circ} \mathrm{C}$ which contained $\mathrm{OH}^{-}$concentrations $>5 \mathrm{~mol} / \mathrm{L}$. In these solutions, the Pu solubility increased with time. This observation was attributed to the air oxidation of a portion of the $\mathrm{Pu}$ from $\mathrm{Pu}(\mathrm{IV})$ to the more soluble $\mathrm{Pu}(\mathrm{V})$ or $\mathrm{Pu}(\mathrm{VI})$ valence states.

A data driven approach was used to develop a modified response surface model for Pu solubility. Solubility data from this study and historical data from the literature were used to fit the model. The $\mathrm{R}^{2}$ value for the fitted model was 0.859 , which indicates that this model explains $>85 \%$ of the variation in the response values. An analysis of variance also indicated no statistically significant lack of fit for the model. The SRNL prediction model was compared with predicted values from the AQ model developed by OLI Systems, Inc. and a prediction equation developed by Delegard and Gallagher for Hanford tank waste. The agreement between measured or values predicted by the SRNL model and values predicted by the OLI AG model was very poor. The much higher predicted concentrations by the OLI AQ model appears to be the result of the model predicting the predominate $\mathrm{Pu}$ oxidation state is $\mathrm{Pu}(\mathrm{V})$ which is reported to be unstable below $\mathrm{NaOH}$ concentrations of $6 \mathrm{M}$. Since the predominant Pu oxidation state in the test solutions in this study is $\mathrm{Pu}(\mathrm{IV})$, the OLI AQ model is not appropriate for predicting the solubility of alkaline salt solutions in equilibrium with $\mathrm{Pu}(\mathrm{IV})$ solids.

There was very good agreement between the predicted Pu concentrations using the SRNL model and the model developed by Delegard and Gallagher with the exception of solutions that had very high $\mathrm{OH}^{-}(15 \mathrm{M})$ concentrations. The lower $\mathrm{Pu}$ solubilities in these solutions was attributed to the presence of $\mathrm{NO}_{3}{ }^{-}$and $\mathrm{NO}_{2}{ }^{-}$which limit the oxidation of $\mathrm{Pu}(\mathrm{IV})$ to $\mathrm{Pu}(\mathrm{V})$. Previous solubility studies have reported a decrease in $\mathrm{Pu}$ solubility with increasing concentrations of $\mathrm{NO}_{3}{ }^{-}$and $\mathrm{NO}_{2}{ }^{-}$.

\section{References}

1. D. T. Hobbs, T. B. Edwards, and S. D. Fleischman, Solubility of Plutonium and Uranium in Alkaline Salt Solutions, Report No. WSRC-TR-93-00056, Westinghouse Savannah River Company, Aiken, SC, February 1993.

2. D. T. Hobbs and T. B. Edwards, Solubility of Plutonium in Alkaline Salt Solutions, Report No. WSRC-TR-93-00131, Westinghouse Savannah River Company, Aiken, SC, February 1993. 
3. C. H. Delegard and S. A. Gallagher, Effects of Hanford High-Level Waste Components on the Solubility of Cobalt, Strontium, Neptunium, Plutonium, and Americium, Report No. RHO-RE-ST-3P, Rockwell Hanford Operations, Richland WA, October 1993

4. V. F. Peretrukhin, S. V. Kryutchkov, V. I. Silin, and I. G. Tananaev, Determination of the Solubility of Np(IV)-(VI), Pu(III)-(VI), Am(III)-(VI), and Tc(IV), (V) Hydroxo Compounds in 0.5 - 14M NaOH Solutions, Report No. WHC-EP-0897, Westinghouse Hanford Company, Richland, WA, September 1996.

5. C. H. Delegard, Solubility of $\mathrm{PuO}_{2} \bullet \mathrm{H}_{2} \mathrm{O}$ in Alkaline Hanford High-Level Waste Solution, Report No. RHO-RE-SA-75P, Rockwell Hanford Operations, Richland WA, May 1985.

6. D. T. Hobbs and T. B. Edwards, Solubility of Uranium in Alkaline Salt Solutions, Report No. WSRC-TR-93-00454, Westinghouse Savannah River Company, Aiken, SC, March 1994.

7. D. A. Reynolds, "Practical Modeling of Aluminum Species in High-pH Waste," Report No. WHC-EP-0872, Westinghouse Hanford Company, Richland, WA (October 1995).

8. Bedrock Waste Storage: Technical Progress Report, February-April, 1972, Report No. DPST-72-122-2, E. I. du Pont de Nemours \& Co., Aiken, SC, July 1972.

9. I. W. Marine, Bedrock Waste Storage: Technical Progress Report, September 1972-June 1973, Report No. DPST-73-122-1, E. I. du Pont de Nemours \& Co., Aiken, SC, October 1973.

10. JMP ${ }^{\circledR}:$ Statistics and Graphics Guide, version 3.0, SAS Institute, Inc., Cary, NC, 1994.

11. Myers, R. H. and D. C. Montgomery, Response Surface Methodology - Process and Product Optimization Using Design Experiments, Second Edition, John Wiley and Sons, Inc., New York, 2002.

12. K. Q. Ye, Orthogonal Column Latin Hypercubes and Their Application in Computer Experiments, Journal of the American Statistical Association, 1998, 93, 1430-1439.

13. D. T. Hobbs and K. G. Karraker, "Recent Results on the Solubility of Uranium and Plutonium in Savannah River Site Waste Supernate,” Nucl. Technol.,114, 318 (1996).

14. JMP ${ }^{\circledR:}$ Statistics and Graphics Guide, version 7.0.2, SAS Institute, Inc., Cary, NC, (2007).

15. OLI Stream Analyzer (Mixed Solvent Electrolyte database), version 2.0.64, OLI Systems, Inc., Morris Plains, NJ (2008). 
16. G.S. Barney and C.H. Delegard, Chemical Species of Plutonium in Hanford Radioactive Tank Waste, Proceedings of an American Chemical Society Symposium on Experimental and Modeling Studies of Actinide Speciation in Non-Ideal Systems, Orlando, FL, United States, August 26-28, 1996 (1999), Meeting Date 1996, 83 - 110. Publisher Kluwer Academic/Plenum Publishers, New York, NY, CODEN:69ACVU. 
Figure 1 Design points for the Pu solubility test matrix and available data

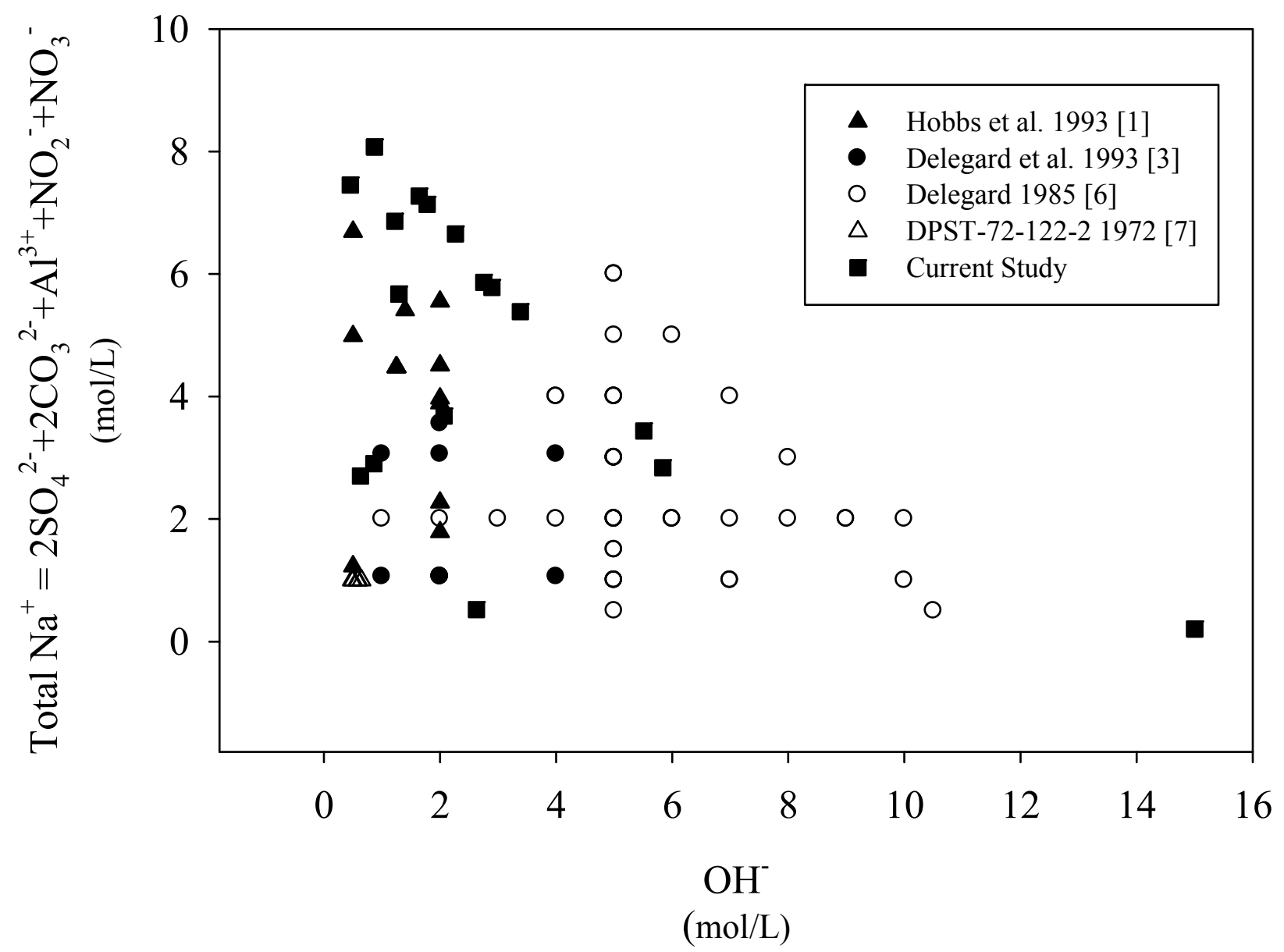


Figure $2 \mathrm{Pu}$ solubility in simulated SRS waste solutions

$$
25{ }^{\circ} \mathrm{C}
$$

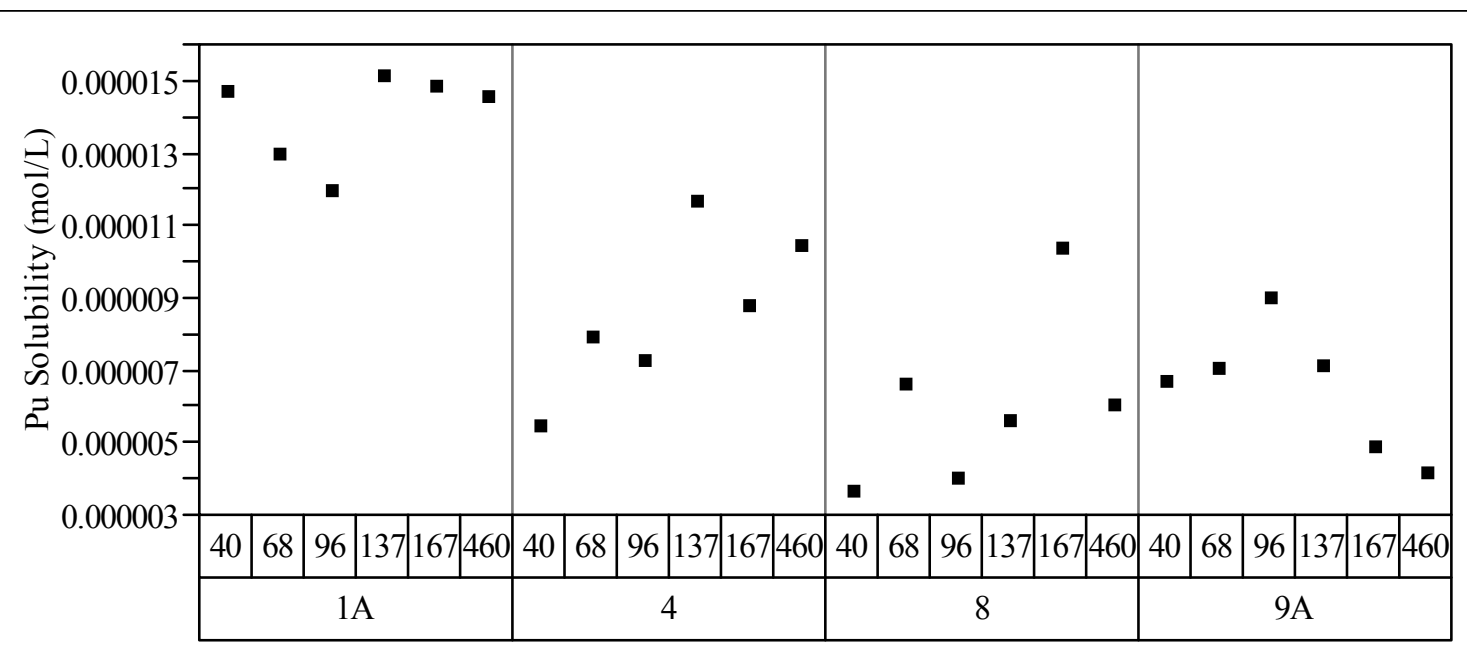

Equilibra. Time (d) within Solution

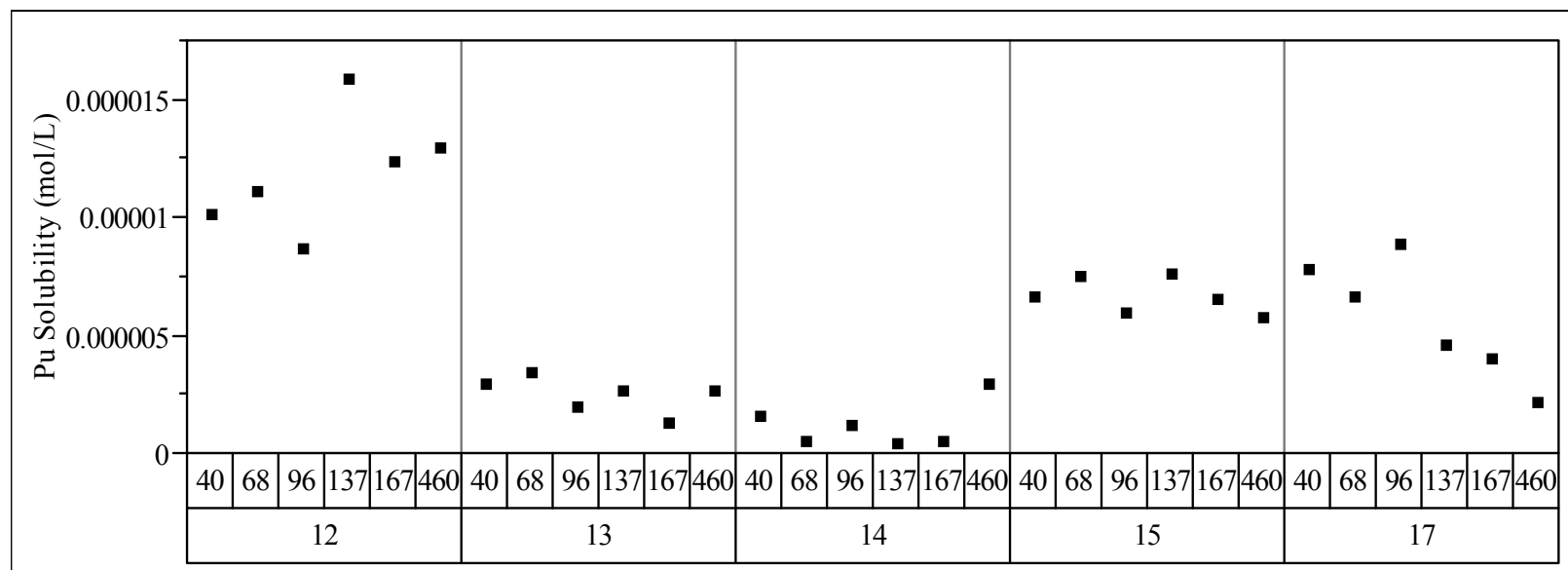

Equilibra. Time (d) within Solution 
Figure $3 \mathrm{Pu}$ solubility in simulated SRS waste solutions

$80{ }^{\circ} \mathrm{C}$
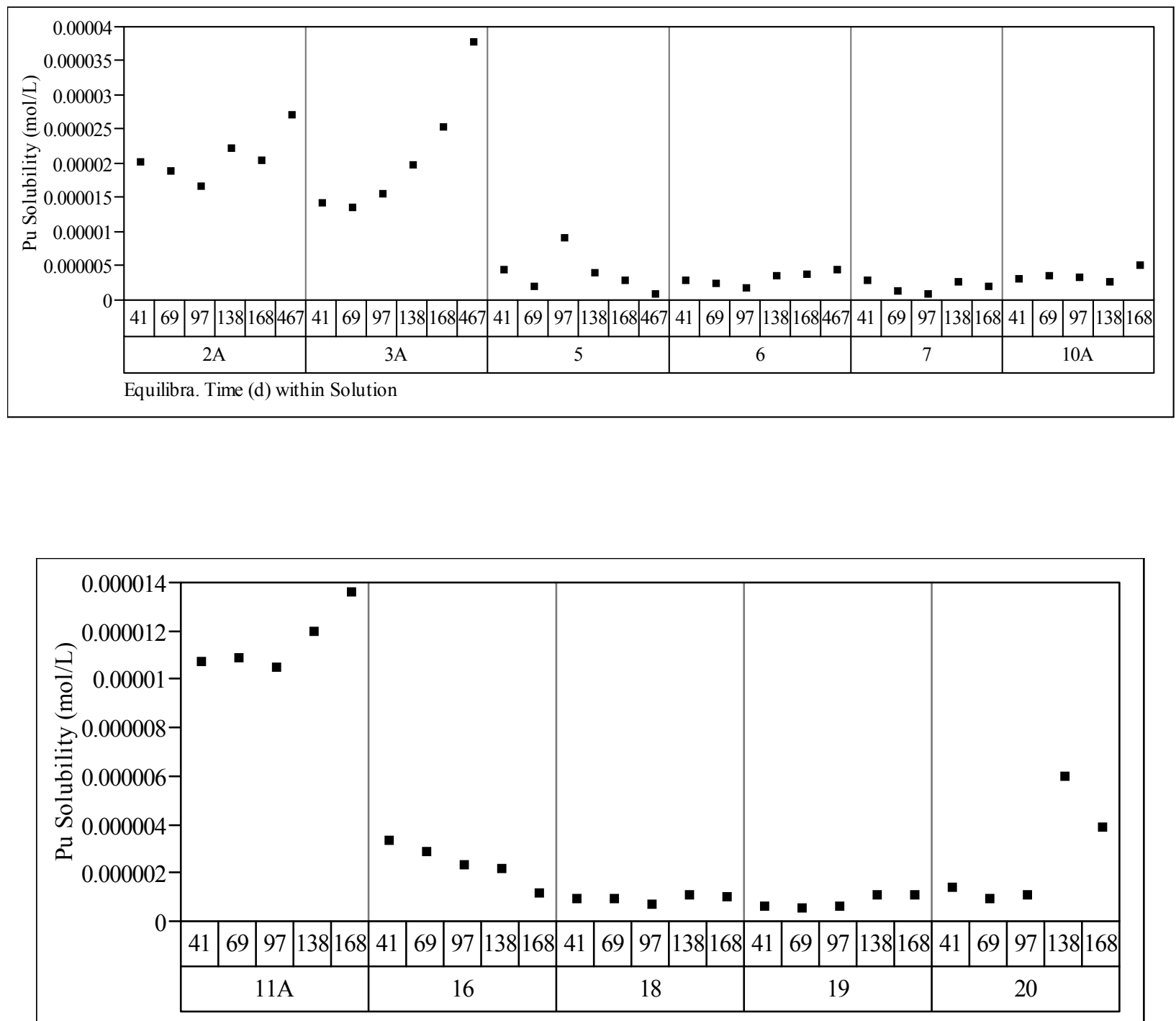

Equilibra. Time (d) within Solution 
Figure 4 Filtration Study Results
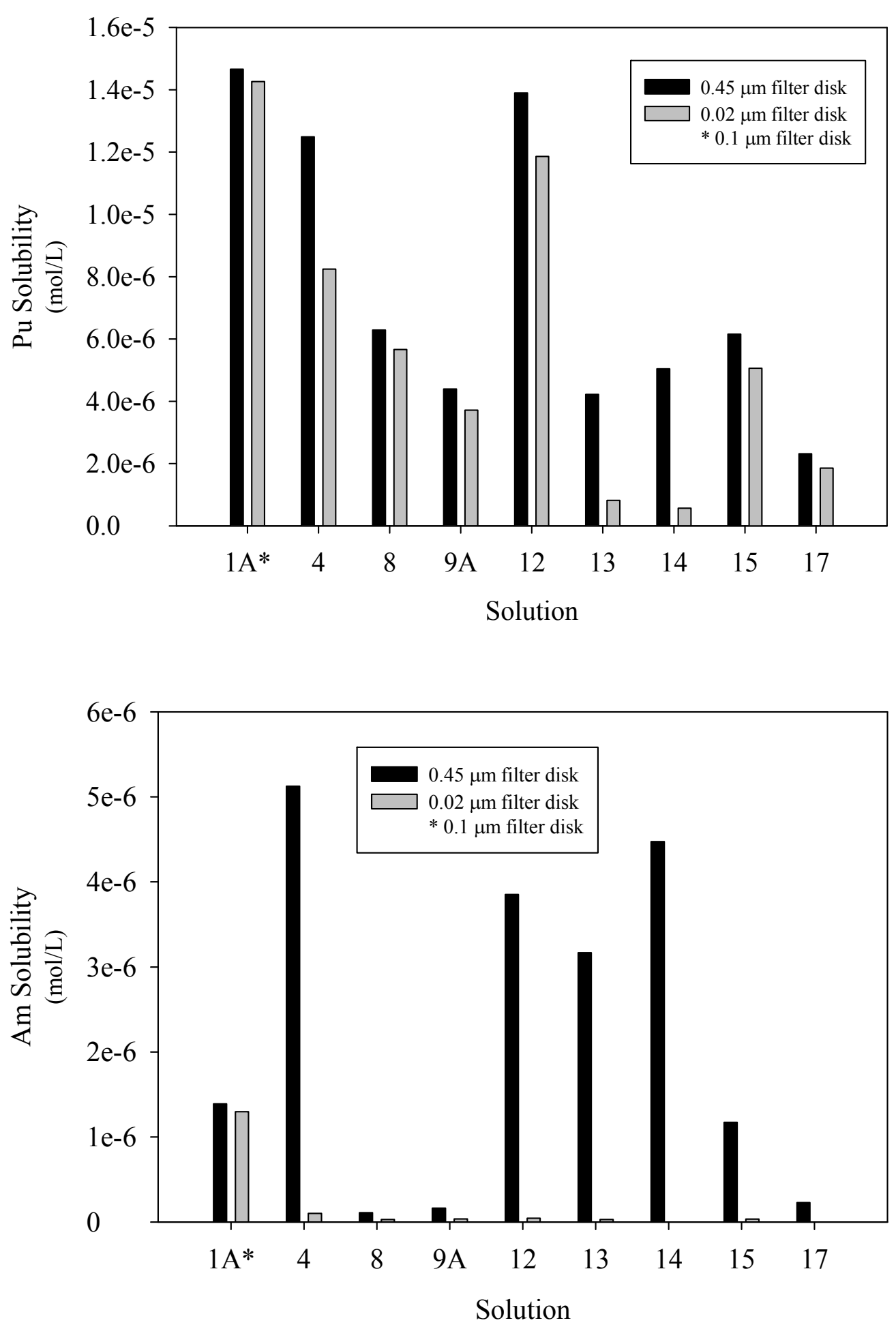
Figure 5 Uncertainty in Pu Solubility Measurements

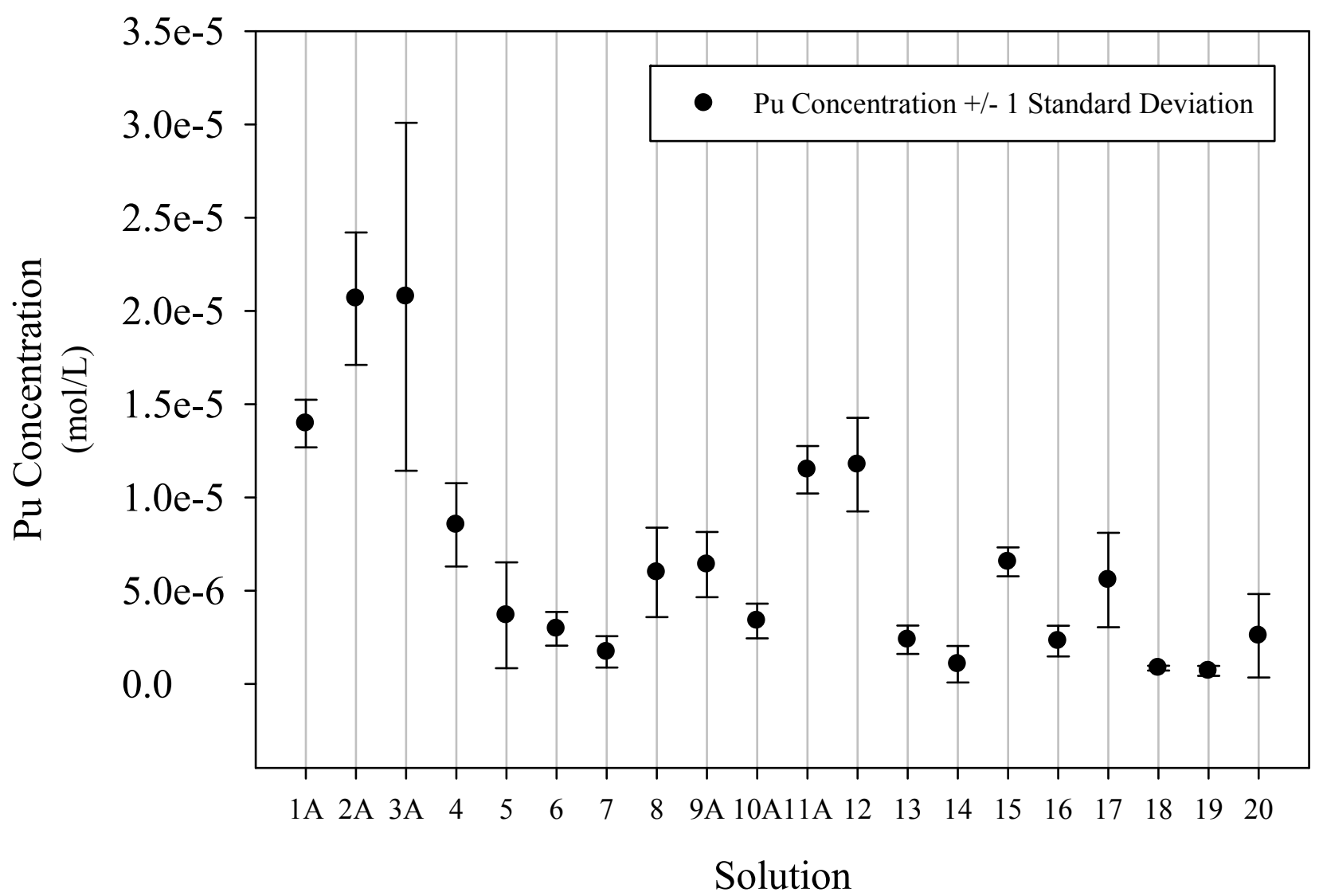


Figure 6 Measured and predicted Pu concentrations using Hanford, OLI AQ, and SRNL response surface models

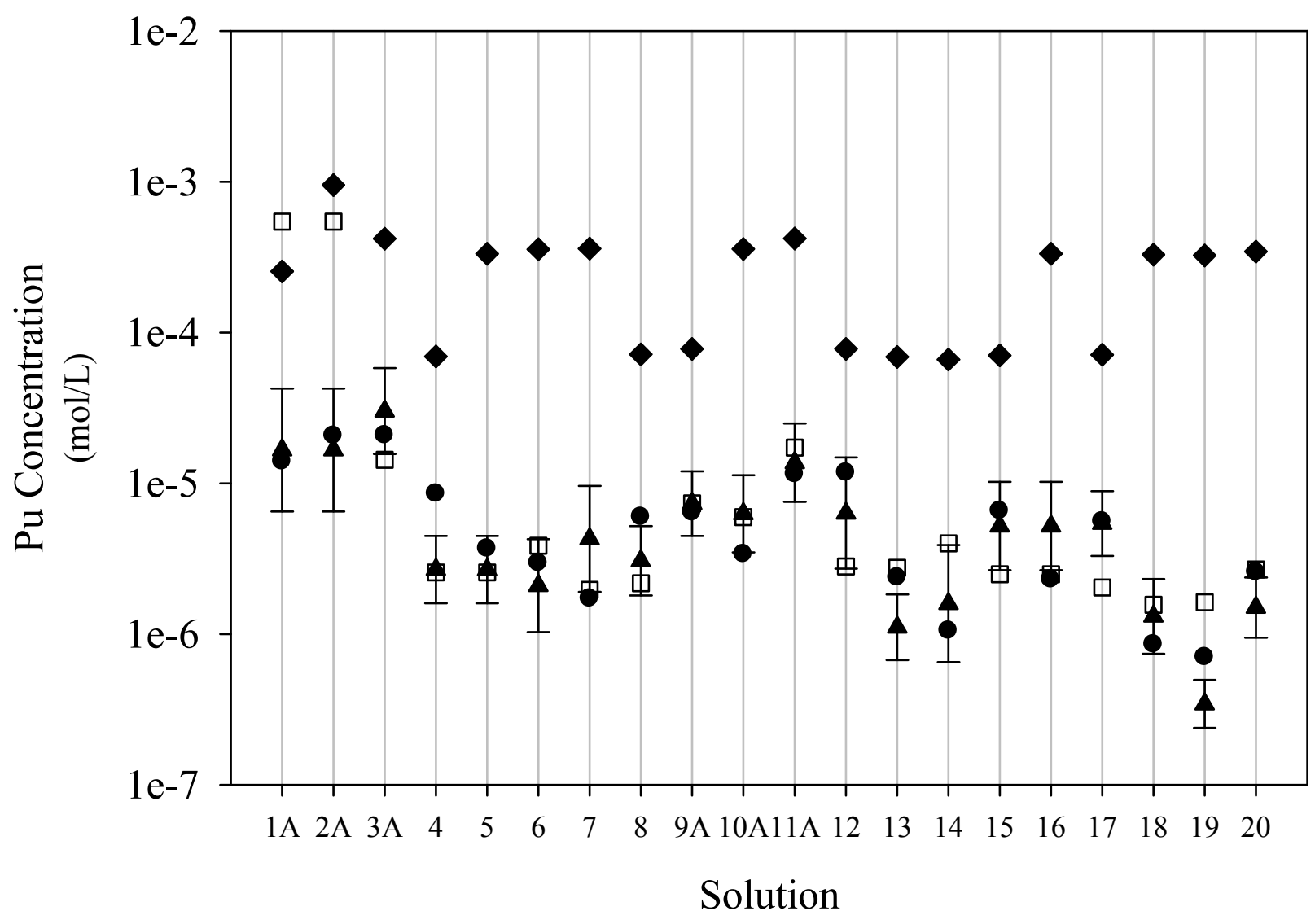

- Measured

- SRNL Model

․ Hanford Model

$\bullet \quad$ OLI AQ Model 